\title{
Automated Warehouse Management Wagon Depot
}

\section{Tolaniddin Ramziddinovich Nurmukhamedov ${ }^{a}$, Javlon Nurullaevich Gulyamov ${ }^{b}$}

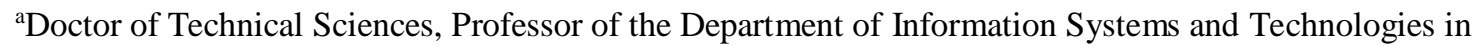
Transport, Tashkent State University of Transport, Tashkent, Uzbekistan.

${ }^{\mathrm{b}}$ Senior Lecturer, Department of Information Systems and Technologies in Transport, Tashkent State University of Transport, Tashkent, Uzbekistan.

Article History: Received: 11 January 2021; Accepted: 27 February 2021; Published online: 5 April 2021

\begin{abstract}
The research paper provides an analytical review of the rational organization of storage in transport, notes the works of scientists that are of great importance for the railway industry, and considers the issues of optimal placement of inventory items in the carriage depot of the Joint Stock Company "Uztemiryulyulovchi" ("Uzdzheldorpass"). The structure of a warehouse reflecting the main elements of technological sections, consisting of an unloading section, a cargo receiving section, a storage area (temporary and main), a picking section, a service and technical room, is presented. The developed mathematical models for determining rational placement, graphs of the effect of the life cycle of goods on the logistics cycle of replenishment of stocks, methods for determining the amount of supply of spare parts for mobile units when managing their stocks are presented.
\end{abstract}

Keywords: Analysis, Carriage Depot, Railway Transport, Moving Units, Automation, System, Element, Goods, Material, Optimal, Costs, Volume, Transportation.

\section{Introduction}

The State Joint Stock Railway Company "Uzbekiston Temir Yullari" was established on November 7, 1994 on the basis of the former Central Asian Railway, located on the territory of the Republic of Uzbekistan. Since 1993, it has been a member of the Organization for Cooperation between Railways (OCR), and in 2015 it was transformed into the Joint Stock Company "Uzbekiston Temir Yullari”.

Railway transport (RT) of the republic with the acquisition of independence has been steadily developing and today new lines have been built and put into operation: Navoi-Uchkuduk, Sultanuvays-Nukus; Toshguzar-BoysunKumkurgan; Angren-Pap. The volume of cargo and passenger traffic is growing from year to year. Thus, as of 01.01.2020, 94.5 million tons of cargo and 23.4 million passengers were transported; the total length of railway tracks is $6950 \mathrm{~km}$; the number of employees and employees of the company is more than 91 thousand people; the freight turnover amounted to 23.4 billion ton-km, and the passenger turnover was 4385 million pass-km.

One of the main links involved in passenger transportation is the railway depot, which are used for repairing rolling stock or for the production of maintenance. The serviced rolling stock determined the types of railway depots: these are carriage depots, electric depots, motor-carriage depots, locomotive and locomotive depots. Simultaneous maintenance of different types of rolling stock, for example, electric trains and electric locomotives, classifies this depot as a mixed type.

Any transport organization engaged in the transportation of goods and passengers needs storage of inventory items (goods and materials), spare parts, inventory using warehouse facilities.

The issues of rational organization of storage facilities in transport, including the determination of the parameters of warehouses, the calculation of the value of their required capacity and processing capacity, the equipment of cargo fronts, were addressed by such scientists as B.A. Anninsky, S.N. Brilliantov, V.V. Golubkov, E. L. Gokhbom, G. P. Grinevich, P. S. Gruntov, G. M. Demichev, A. T. Deribas, A. Kablukov, V. N. Kustov, S. I. Loginov, O. B. Malikov, Yu.A. Perten, V.V. Povorozhenko, V. M. Semyonov, A. A. Smekhov, A. G. Usov, V. A. Frolova, V. P. Yaroshevich and others [3, 13, 17, 25, 28]. The study of unevenness of car traffic, damping of fluctuations in freight traffic and the interaction of railway and other types of transport through transshipment warehouses at freight stations, are reflected in the scientific works of such scientists as V. M Akulinichev, V. A. Kudryavtsev, V. Ya. Negrey, N. V. Pravdin, AK Ugryumov, NI Fedotov, IG Tikhomirov, and others [10, 19]. At the present stage, scientific research in the field of transport logistics has allowed a number of scientists, such as B.A. Anikina, V.V. Baginova, A.S. Balalaeva, A.M. Gadzhinsky, V.V. Dybskaya, N.D. Ilovaisky, V.P. Klepikova, R.G. Leontyeva, V. S. Lukinsky, S. V. Miloslavskoy, L. B. Mirotin, Yu. M. Nerush, V. M. Nikolashina, Yu. Pazoisky, M.B. Petrova, K.V. Puzhnikova, T.A. Prokofieva, A.N. Rakhmangulova, S. M. Reser, N. Rodnikov, A. 
I. Semenenko, V. I. Sergeev and many others, to determine the important place of freight terminals in the overall transport and logistics chain (TLC) for the delivery of goods [2, 5, 11, 12, 15, 20, 23, 24].

The works of A.F. Borodin, S.Yu. Eliseeva, V.A. Kudryavtseva, P.V. Kurenkova, B.A. Lyovina, A.T. Osminina, V.A. Persianova, S.M. Reser, dedicated to the improvement of transport and logistics technologies for the delivery of goods $[6,10,16,20,27]$.

In the formation of the theory of transport and cargo systems, the design of the layout and technical equipment of transport nodes, scientists contributed: I.S. Besedin, G.P. Grinevich, V.N. Degtyarenko, N.P. Zhuravlev, Yu.V. Korovyakovskaya, O.B. Malikov, G.P. Manzhosov, A.K. Pashkov, Yu.I. Ryzhikov, A.A. Smekhov, O. N. Numbers and others $[3,4,7-9,13,14,18,21,25]$.

Abroad, the formation of transport and logistics systems was dealt with by such scientists as: Bowersox D. J.; Christopher M.; Fechner I.; Ferguson M.R.; Ford L. R.; Fulkerson D. R.; Higgins C.D.; Kloss D.A.; Lambert D.M.; Linders M.; Medda F.; Middendorf D.; Musso A.; Notteboom T.; Potthof G.; Stock J.R.; Richards G.; Rodrigue J.P.; Roso V.; Rushton A. and many others [1, 26].

An analytical review of the considered works made it possible to establish a number of unsolved problems in the research of warehouse facilities at ZhT. So, for example, due attention was not paid to the importance of warehouses on railways, as tools for organizing cargo flows and objects through which the interaction of various modes of transport is carried out. In a fairly large number of developed methods for calculating the parameters of warehouses, including capacity and processing capacity, there are a number of common simplifications for them, such as the use of the coefficient of unevenness, average values of cargo flows of arrival and departure, standard storage times. The noted simplifications lead to inaccurate calculation of one of the most important parameters of the warehouse - capacity.

A wagon depot warehouse is a complex technical system, consisting of the following elements: a warehouse building, equipment for storing and moving goods, the goods themselves, the staff of the warehouse, the current warehouse operation technology, a warehouse management subsystem. Like any warehouse, a railway warehouse consists of several elements - technological sections, the interconnection of which gives the warehouse system integrity, orderliness and organization of functioning. The main elements of the warehouse of the carriage depot technological areas consist of the following elements: unloading area, cargo receiving area, storage area (temporary and main), picking area, front for issuing goods and materials, empty container warehouse, service and technical premises.

The task of each separate section is to perform its functions; for this, each section of the warehouse is equipped with special equipment that ensures the implementation of these functions with minimal costs. The tasks of each separate site are subordinated, in turn, to the general goal set for the warehouse.

It should be noted that the warehouse of the carriage depot VChD-2 of JSC "Uztemiryulyulovchi" has a simpler structure with a rather smaller number of its main (warehouse) elements. When considering a warehouse as a complex of elements - technological sections, the structure of the warehouse system can be considered the spatial arrangement of the warehouse sections, their relative position in relation to each other, but this approach will be important in the design of both individual technological sections and the warehouse generally.

From the point of view of the functioning of the warehouse, under the structure of the warehouse system, it is possible to represent the technological links between the sections of the warehouse, expressed in within the warehouse cargo flows and information flows.

The structure of the warehouse is hierarchical (multilevel), it consists of various connections between the elements of the system. Moreover, each system is included in a more complex system, thus becoming a system of a lower order (subsystem). Each element of the warehouse system - a technological section can be considered as a separate system, and can be subjected to a more detailed analysis in order to better study a specific technological section. For example, a section for unloading goods arriving at a warehouse can be considered as a system consisting of separate elements: arrival transport (road, rail, water, etc.), cargo ramp, unloading mechanisms (carts, conveyors, electric forklifts), canopy over the loading ramp, etc. In turn, such an element as a cargo ramp can also be considered as a system consisting of the following elements: a receiving area for unloading a separate transport 
unit (car, car), a hydraulic rocker bridge for leveling the level of the cargo ramp with the floor of the transport unit, automatic gates for vehicles, devices for sealing openings (in refrigerated warehouses), etc.

For the uninterrupted organization of the movement of mobile units - passenger cars, timely and high-quality service of cars at the points of technical inspection and their preparation for flights is necessary. Availability of the necessary goods and materials, spare parts and other necessary equipment allows you to timely prepare passenger trains for flights. Based on this, determining the size of the stock of necessary goods and materials and spare parts of the carriage depot is an urgent task. The availability of the required amount of inventory, spare parts, components has a significant impact on the rhythmic and efficient operation of the carriage depot. Therefore, when organizing warehouse work, servicing depot workers, it is important to determine the optimal value (size) of the supply of goods and materials, since this value affects the uniform production process. If the size of the order of goods and materials is small, then on a certain day it may not be in the warehouse, which in turn will negatively affect the uniformity of performance of certain operations for servicing passenger cars. It should be noted that if the order size is large and exceeds the product life cycle, then the depot warehouse will receive an obsolete inventory of goods and materials and will also incur losses. Consequently, the inventory of the warehouse must correspond to demand and the availability of products must determine the optimal amount of supply, take into account the life cycle of the goods, the logistics cycle of replenishment and the size of the order.

Analysis of work on optimizing the size of the enterprise's stock shows that to determine the optimal supply of goods and materials, it is necessary to use the existing inventory management policy, which consists of two main methods: the analytical method and modeling the inventory management system.

As the initial data when calculating the optimal stocks in the warehouse of the carriage depot, the following should be taken into account: the logistics system (its characteristics), the target level of service (delivery time, quality of goods and materials), characteristics of the functional cycle and demand. The proposed model also makes it possible to determine the parameters of inventory management, one of which is the size of the order (optimal delivery value). The initial data for modeling the inventory management system are the parameters of inventory management (safety stock, order point and order size (optimal delivery value). As a result of modeling, it is possible to obtain not only the order size and other parameters, but also to determine the level of service and characteristics of inventory management (demand, cycle and logistics system).

In the theory of inventory management, several systems are distinguished. Their regulation depends on the initial parameters that govern the stocks. Most often, such parameters are taken as order sizes for replenishment of stocks, order frequency, supported stock level, stock level fluctuations, etc.

\section{Statement of the Problem of Determining the Size of Stocks in the Carriage Depot}

\section{Determining the Optimal Size of the Current Stock}

Consider the procedure for determining the optimal size of the current stock of one item. The nature of the current stock is reflected in its name "current". Indeed, ensuring the uninterrupted functioning of the carriage depot in the periods between successive deliveries, this category of stock seems to flow out of the warehouse, changing its value at each consumption. Speaking about the size of the current stock, as a rule, they mean its maximum, average or minimum value. If a new batch of consumable goods and materials arrives exactly at the end of the previous one, the minimum value of the current stock will be zero, and the average value will be half the maximum. Obviously, in this mode of supply, the maximum current stock will be equal to the size of the delivered consignment. In fig. 1 shows how over four quarters ( $0 \mathrm{X}$ axis) as consumption and delivery, the size of the current stock (0Y axis) changes from 1800 to 0 units.

The optimal size of the current stock will be considered the optimal value of its average value (Ztek.av), equal to half of the ordered and delivered batch of goods. In this way, the problem of finding the optimal stock size is transformed into the problem of finding the optimal size of the ordered batch of goods.

The optimum criterion is the minimum total costs for the period associated with the creation and maintenance of the stock. 


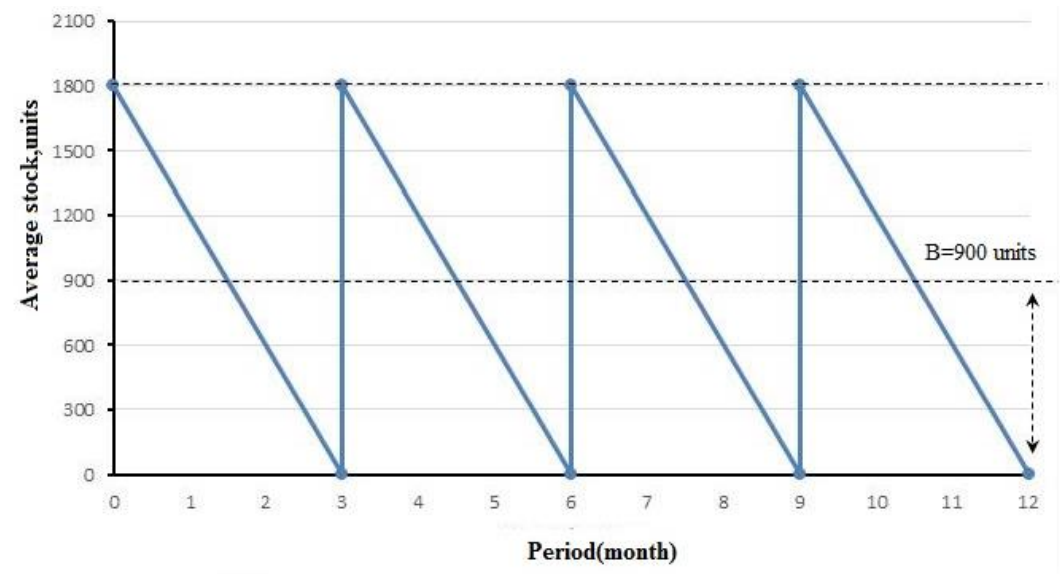

Figure: 1. Changing the size of the current stock

1. The current maximum stock is 1800 units.

2. The current minimum stock is 0 units.

3. The current average stock is 900 units.

Inventory management systems use two categories of costs: unit costs and costs for the analyzed period.

\section{Specific costs represent:}

- Specific costs for the creation of stocks, i.e. the cost of placing and receiving one order, measured in rubles and indicated by the symbol $\mathrm{K}$;

- Specific costs for storing stocks, i.e. costs of storing a unit of stock per unit of time, denoted by the symbol $\mathrm{M}$ and have the dimension of sum / sum * year or 1 / year if the stock is measured in monetary units.

In inventory management systems, a year is most often taken as a unit of time when determining unit storage costs. Thus, the value $M$ shows what part of the cost of a unit of production is the cost of its storage during the year. For example, if the purchase value of an item is 82,020 soums, and $M=0.31$ / year, this means that the storage of one item during the year costs the company 180 soums.

Costs for the period are:

- $\quad$ Costs of placing and receiving all orders made for the period (Szak);

- Costs of storing the average stock during the period (storage).

The total costs for the period will be denoted by the symbol Common. Costs for a period are measured in sum / period, for example, sum / year.

In addition to unit costs and costs for the period, the inventory management system is also characterized by the following parameters:

- $\quad$ Q - demand for goods and materials for the analyzed period, pcs / period;

- $\quad$ P - purchase cost of a unit of goods and materials, sum / piece;

- $\quad \mathrm{T}$ - duration of the analyzed period, year / period;

- $\quad \mathrm{S}$ - the size of the ordered batch of goods and materials, pcs;

- $\mathrm{Z}_{\mathrm{a} . \mathrm{c}}$ - current average stock, pcs;

- $\quad \mathrm{N}$ - the number of orders for the period (delivery frequency), order / period;

- $\mathrm{t}$ - interval between deliveries, year / order.

The objective function can be represented as follows:

$$
C_{\text {tot }}=F\left\{C_{\text {storage, }} C_{\text {bookings, }} M, K, Q, P, S, B \text { a.c., } N, t\right\} \rightarrow \min
$$

The uncontrollable parameters in the objective function are obviously the unit costs of stock creation $(\mathrm{K})$ and unit costs of stock storage $(\mathrm{M})$, as well as the demand for the product for the analyzed period $(\mathrm{Q})$, the purchase cost of a unit of the product $(\mathrm{P})$ and the duration of the analyzed period $(\mathrm{T})$. 
The remaining parameters, closely related to each other, are controllable within the framework of the problem under consideration, i.e. the manager can change them at his discretion, receiving certain economic results.

Note that the optimization problem can be solved if the following conditions are met:

- new batch of goods is delivered at the time of full consumption of the current stock;

- the demand for materials for the period (demand for goods) is a known and constant value ( $\mathrm{Q}=$ const);

- unit costs for creating stocks are known and constant $(\mathrm{K}=$ const $)$, i.e. the cost of placing and receiving one order does not depend on the size of the order;

- $\quad$ unit costs of stock storage are known and constant $(\mathrm{M}=$ const $)$;

- the purchase cost of the goods is constant and does not depend on the size of the purchased batch $(\mathrm{P}=$ const).

The criterion for the optimum, as already noted, is the minimum amount of total costs for the period. In this regard, we represent the objective function (1) as the sum of costs for the period for the creation and storage of stocks and find such a value of the order size (Sonm), at which the total costs will be minimal.

$$
C_{\text {tot }}=\mathrm{C}_{\text {stor }}+\mathrm{C}_{\text {bookings }} \rightarrow \min .
$$

To solve the problem, we will find the dependences of $S_{\text {bookings }}$ and $S_{\text {bookings }}$ on order size $S$.

Dependence of costs for the period for creating stocks on the size of the order.

The number of orders for the period $(\mathrm{N})$ is related to the demand for the product for the corresponding period (Q) and the size of the order (S) as follows:

$$
N=Q / S
$$

The costs for the period associated with placing and receiving orders will be determined by the formula:

$$
\text { Cbookings }=N^{*} K,
$$

Or substituting the value $\mathrm{N}$ from the above formula, we can write:

$$
\mathrm{C}_{\text {bookings }}=\frac{Q}{S} * K
$$

Formula (3) shows that a change in the order size (S) entails a change in the number of orders and a corresponding change in costs for the period associated with placing and receiving orders $\left(S_{\text {bookings }}\right)$. Analysis of the obtained results presented in Fig. 2 allows us to conclude that the graph of the dependence of $S_{\text {bookings }}$ on $S$ has the form of a hyperbola.

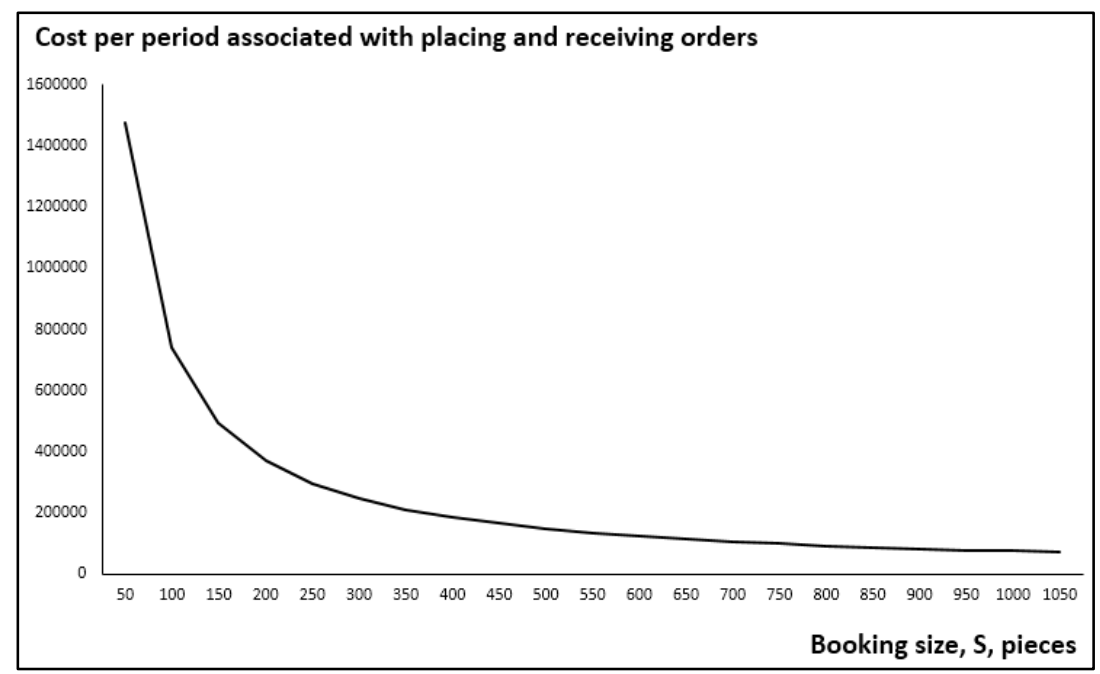

Figure: 2. Dependence of costs for the period associated with placing and receiving orders from the size of the order. 
Accordingly, a change in the order size affects the change in the average value of the current stock $\left(\mathrm{Z}_{\text {texr }}\right)$, as well as the costs for the period of its storage $\left(S_{\text {str }}\right)$. For example, if in our example we order not 1800 units. (see Fig. 4), and for 7200 units, the number of orders per year will decrease from four to one, and the average stock will increase from 900 to 3600 units. Accordingly, the annual storage costs will increase by 4 times.

The costs for the period for storing stock are determined by the formula:

$$
\mathbf{C}_{\text {stor }}=\mathbf{M} * \mathbf{T} * \mathbf{B}_{\text {per.s. }} * \mathbf{P}
$$

Substitution of the dimensions of the quantities included in the formula, which the reader is invited to perform independently, will allow you to more clearly represent the dependence and make sure the formula is correct.

It is known that the average value of the current stock is equal to half of the order, i.e.

$$
B_{\text {per. } . v}=\frac{S}{2}
$$

Hence, the costs for the period for storing stock can be determined by the formula:

$$
\mathrm{C}_{\text {stor }}=\mathbf{M} * \mathbf{T} * \frac{\mathbf{s}}{2} * \mathbf{P} \text {. }
$$

The graph of the dependence of $\mathrm{C}_{\text {stor }}$ on the order size $\mathrm{S}$, which, as a rule, has a linear shape, is shown in.

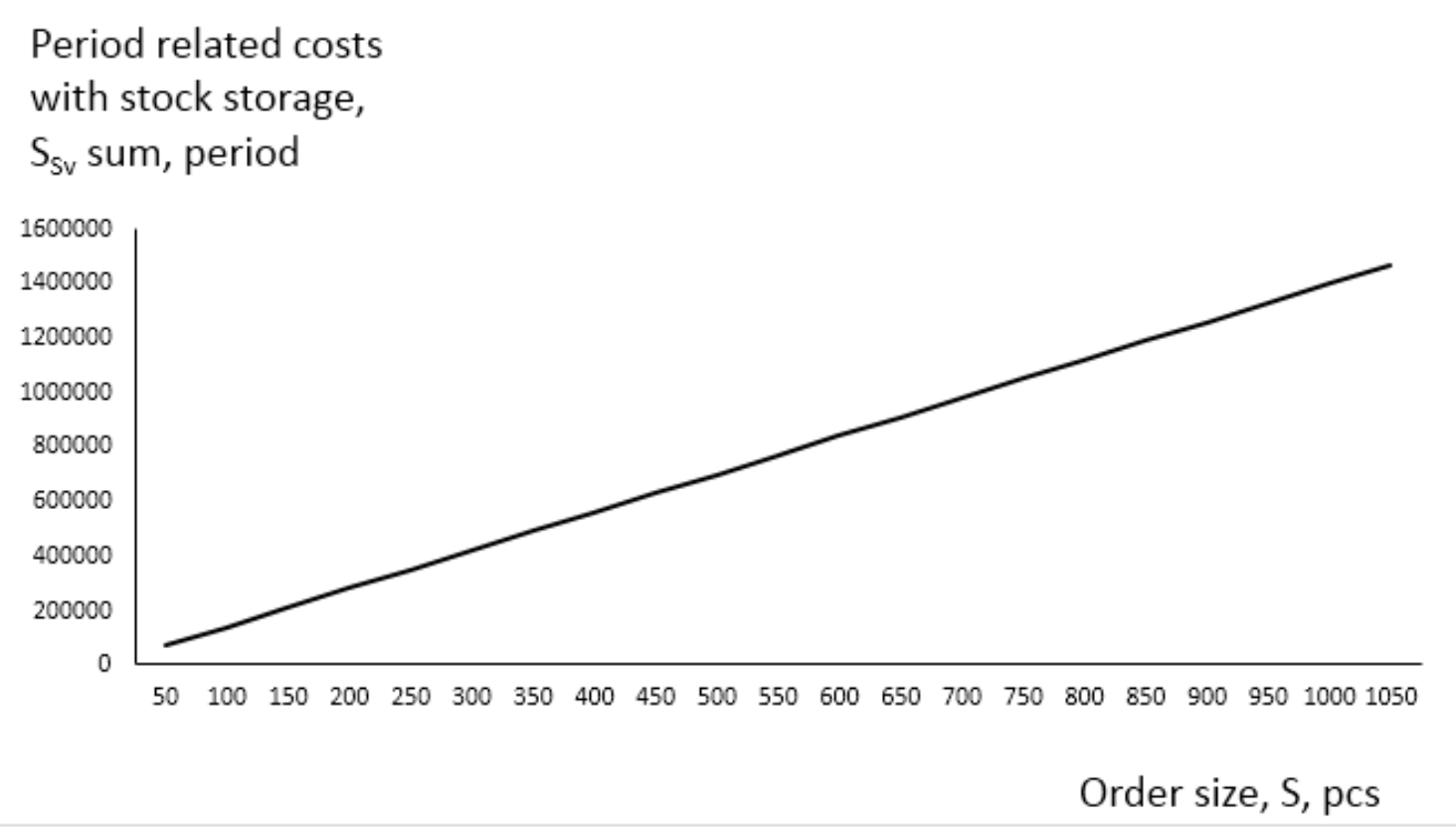

Figure 3. Dependence of the costs for the period associated with the storage of stocks on the size of the order

As you can see, changing the order size entails a change in the costs for the period both for creating stock and for storing it. However, the nature of the dependence of each of these cost items on the order size is different. The total costs for the period for creating a stock with an increase in the order size obviously decrease, since purchases are made in larger quantities and, therefore, less frequently. Storage costs increase over the period in direct proportion to the size of the order.

Graphically, the dependence of the total costs for the period associated with placing and receiving orders, as well as with storing stock, on the size of the order is shown in Fig. 4. 


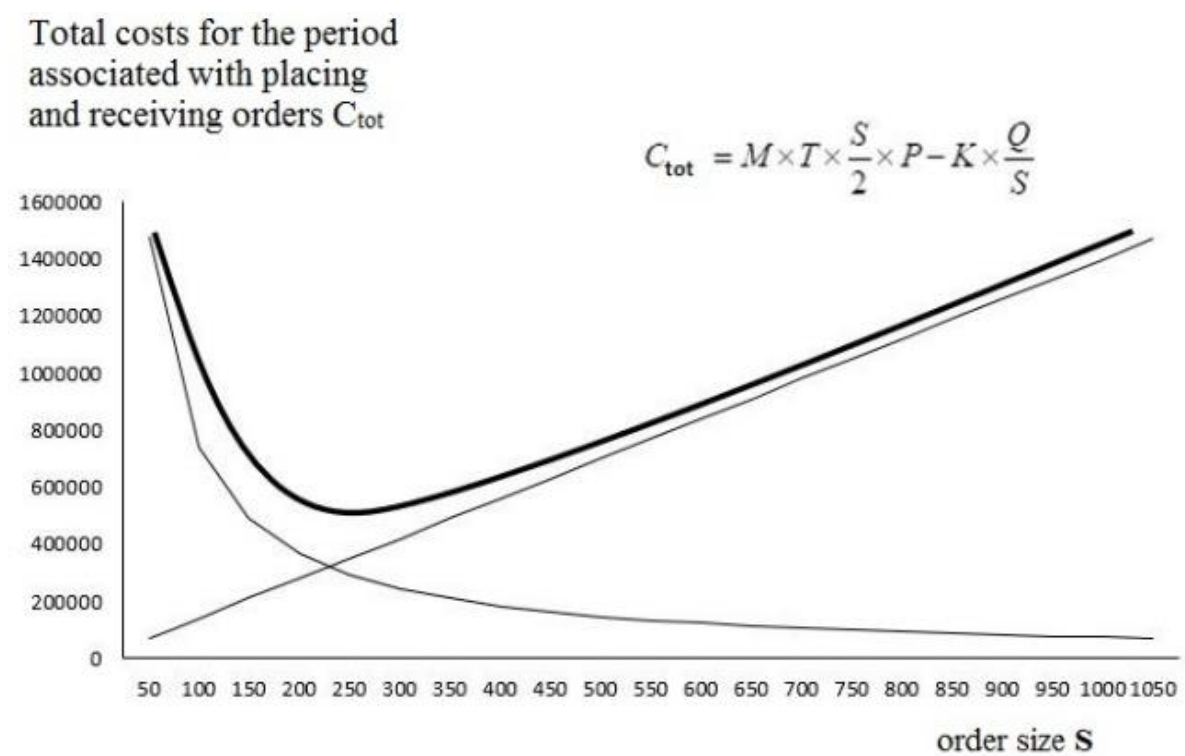

Figure 4. Dependence of the total costs for the period associated with placing and receiving orders, as well as with the storage of stock, on the size of the order

Let's determine the order size (S), which minimizes the total costs. Substituting formulas (3), (4) into the formula for total costs (2), we get:

$$
\mathrm{C}_{\text {tot }}=\mathrm{M} * \mathrm{~T} * \frac{S}{2} * \mathrm{P}+\mathrm{K} * \frac{Q}{S} \rightarrow \min
$$

The formula (shows) that in this equation there are two controlled parameters: $\mathrm{S}$ - the independent variable and $\mathrm{S}_{\mathrm{dv}}$ - the dependent variable. The rest of the parameters are constant coefficients. After simplifications, formula (5) is presented in the following form:

$$
\mathrm{C}_{\text {tot }}=a * S+\frac{b}{s}
$$

Where $a=\frac{M * T * P}{2}, b=K * Q$

The total cost function has a minimum at the point where its first derivative with respect to $\mathrm{S}$ is zero and its second derivative is greater than zero. Let's find the first derivative for $\mathrm{C}_{\mathrm{tot}}$ :

$$
C_{t o t}^{\prime}=a-\frac{b}{S^{2}} .
$$

Find the value $\mathrm{S}$ that turns the derivative of the objective function to zero:

$$
a-\frac{b}{S^{2}}=0
$$

Hence the order size $\mathrm{S}$ will be equal to:

$$
S=\sqrt{\frac{b}{a}}
$$

The check shows that the second derivative is greater than zero, therefore, the obtained value of S provides a minimum of total costs for creating stock and its storage.

Substituting the values of a and b into expression (7), we obtain a formula that allows us to calculate the optimal order size, which in the theory of inventory management is known as the Wilson formula:

$$
S_{o p t}=\sqrt{\frac{2 * Q * K}{M * T * P}}
$$


Using formula (8), we determine the optimal values of the remaining controlled parameters.

The optimal amount of costs for the period $\mathrm{T}$ for the creation of stock $\left(\mathrm{S}_{\text {opt.fin }}\right)$ :

$$
\mathrm{C}_{\text {opt.fin }}=\mathrm{K} \frac{Q}{S_{\text {opt }}}
$$

substituting Sopt from formula (8) we get:

$$
\mathrm{C}_{\text {opt.fin. }}=\frac{K * Q}{\sqrt{\frac{2 * Q * K}{M * T * P}}}
$$

After the appropriate transformations, we get the final formula for the optimal size of the cost of creating stock

$$
\mathrm{C}_{\text {opt.fin }}=\frac{1}{\sqrt{2}} \sqrt{Q * K * M * T * P}
$$
form:

The optimal amount of costs for the period $\mathrm{T}$ for storage of stock $\left(\mathrm{S}_{\text {opt.storage }}\right)$ according to formula (4) has the

$$
\mathrm{C}_{\text {opt.storage }}=\mathrm{M} * \mathrm{~T} * \frac{S_{\text {onT }}}{2} * \mathrm{P} .
$$

Substituting Sopt from formula (8) we get:

$$
\mathrm{C}_{\text {opt.stor }}=\frac{1}{2} * \mathrm{M} * \mathrm{~T} * \mathrm{P} * \sqrt{\frac{2 * Q * K}{M * T * P}}
$$

After the appropriate transformations, we obtain the final formula for the optimal costs of stock storage

$$
\mathrm{C}_{\text {opt.stor }}=\frac{1}{\sqrt{2}} \sqrt{Q * K * M * T * P}
$$

The minimum (aka optimal) amount of total costs for the period for the creation and storage of stock $\mathrm{C}_{\text {min.total }}$ is the sum of the optimal costs of creating a stock and their storage:

$$
C_{\text {min.tot }}=\mathrm{C}_{\text {opt.fin }}+\mathrm{C}_{\text {opt.stor }}=\sqrt{2 * Q * K * M * T * P}
$$

From formulas (8) and (9) it follows that at the point of minimum total costs, the costs of creating stock for the period are equal to the costs of storing the stock (for the same period). This implies a conclusion that has significant practical significance: if during the period the costs associated with the creation of stock were equal to the costs of their storage, it means that the goods were purchased optimal, i.e. in correct batches.

The optimal size of the average value of the current stock.

$$
3_{\text {opt.stock }}=\frac{\boldsymbol{S}_{\mathrm{opt}}}{2} .
$$

The optimal number of orders for the period (frequency of delivery).

$$
N_{\text {opt }}=\frac{Q}{S_{\text {opt }}} .
$$

Optimal period between deliveries

\section{Results}

$$
t=\frac{T}{N_{o p t}}
$$

The resulting value of the period between deliveries has an annual measurement: 


$$
\frac{\text { year }}{\text { period }}: \frac{\text { order }}{\text { period }}=\frac{\text { year }}{\text { order }}
$$

Those. the gap between orders is measured in years. In practice, it is more convenient to measure the period between deliveries in months or days. The calculation formula in this case has the form

or

$$
t=\frac{12 * T}{N_{\text {опт }}} \frac{\text { month }}{\text { deliv }}
$$

$$
t=\frac{365 * T}{N_{\text {opt }}} \frac{\text { days }}{\text { deliv }} \text {. }
$$

Let us determine the optimal sizes of the controlled parameters. For this purpose, consider an example in which we assign specific numerical values to uncontrollable parameters (Table 1).

Table 1. Data for calculating the optimal stock size

\begin{tabular}{|l|l|l|l|}
\hline $\begin{array}{l}\text { Indicator: } \\
\text { Product demand for the analyzed period }\end{array}$ & Designation Q & $\begin{array}{l}\text { unit of measurement } \\
\frac{p .}{\text { period }}\end{array}$ & $\begin{array}{l}\text { Value } \\
1800\end{array}$ \\
\hline Unit costs of stock creation & $\mathrm{K}$ & sum & 8350 \\
\hline Unit costs of stock storage & $\mathrm{M}$ & $\frac{1}{\text { year }}$ & 0,3 \\
\hline $\begin{array}{l}\text { The duration of the analyzed period in the soda } \\
\text { dimension }\end{array}$ & $\mathrm{T}$ & $\frac{\text { year }}{\text { period }}$ & $\begin{array}{l}0,25 \\
\text { (one quarter) }\end{array}$ \\
\hline Purchase cost per unit & $\mathrm{P}$ & $\frac{\text { sum }}{\text { pieces }}$ & 82020 \\
\hline
\end{tabular}

The optimal size of the ordered batch will be:

$$
S_{o p t}=\sqrt{\frac{2 \times 1800 \times 68350}{0.3 \times 0.25 \times 82020}}=200 p c
$$

The optimal amount of costs for the period $\mathrm{T}$ for the creation of stock

$$
\begin{gathered}
C_{\text {opt.size. } \cos t} t=\sqrt{\frac{1800 \times 68350 \times 0,3 \times 0,25 \times 82020}{\sqrt{2}}}=615150 \frac{\text { sum }}{\text { quarter }} \\
C_{\text {opt.tot }}=615150+615150=1230300 \frac{\text { sum }}{\text { quarter }} \\
N_{\text {opt }}=\frac{1800}{200}=9 \frac{\text { bookings }}{\text { quarter }} \\
t_{\text {opt }}=\frac{365 \times 0,25}{9} \approx 10 \frac{\text { days }}{\text { bookings }} \\
3_{\text {opt.ave }}=\frac{200}{2}=100 \text { p.c. }
\end{gathered}
$$

The optimal amount of costs for the period $\mathrm{T}$ for stock storage is calculated using a similar formula:

- the minimum (optimal) amount of total costs for the period for the creation and storage of stock;

- the optimal size of the average value of the current stock;

- the optimal number of orders for the period (delivery frequency);

- the optimal period between orders (let's calculate this parameter in days). 


\section{Conclusion}

Note that the above formulas and the corresponding calculations are performed on the assumption that the demand for the analyzed period, as well as the size of the order, are calculated in kind (in pieces). The calculations will not undergo significant changes if we go to the monetary expression of the demand and the order. Here is an example of a calculation based on the fact that the demand for the period in monetary terms $\left(Q^{\text {day }}\right)$ is:

$$
Q^{\text {day }}=1800 \frac{\text { pieces }}{\text { period }} \times 82020 \frac{\text { sum }}{\text { pieces }}=147636000 \frac{\text { sum }}{\text { period }}
$$

Since the size of the order, measured in monetary units $\left(\mathrm{S}^{\mathrm{AY}}\right)$, is equal

$S^{d a y}=S \times P$

the formula for calculating the costs for the storage period (formula 1) will take the form $C_{\text {stor }}=M \times \frac{S^{\text {day }}}{2} \times T$

By making the appropriate changes to formula (1) and carrying out subsequent transformations (see formulas 2,3 and 4), we obtain a model for calculating the optimal order size in monetary terms:

$$
S_{\text {opt. }}^{\text {day }}=\sqrt{\frac{2 \times Q^{d s y} \times K}{M \times T}}
$$

Hence, the optimal order size in monetary terms will be:

$$
S_{\text {opt. }}^{\text {day }}=\sqrt{\frac{2 \times 147636000 \times 68350}{0.3 \times 0.25}}=16404000 \mathrm{sum}
$$

Formulas for calculating the rest of the controlled parameters remain unchanged. For the considered example, we have determined the optimal delivery conditions. If the results obtained are not taken into account, this will lead to overstated costs. Let the delivery of goods be carried out not once every ten days for 200 pieces, but once a month for 600 pieces. In this case, the total costs for the period for creating and storing stock will be:

$$
C_{\text {tot }}=0,3 \times \frac{600}{2} \times 82020 \times 0,25+68350 \times \frac{1800}{600}=2050500 \frac{\text { sum }}{\text { quarter }}
$$

Therefore, the total costs for the period for creating and storing stock for $\frac{2}{3}(67 \%)$ exceed quarterly costs ( $120000 \frac{\text { sum }}{\text { quarter }}$ ) obtained according to the optimal delivery schedule.

\section{References}

1. Bowersox D.J., Kloss D.J. (2005). Logistics Integrated supply chain - M: Olymp Business, 640.

2. Gadzhinsky A.M. (1995). Basics of logistics: Textbook. Allowance. - M: IVTs "Marketing", 124.

3. Grinevich, G.P. (1987). Complex mechanized and automated transport warehouses: 3rd ed., Revised and enlarged. G.P. Grinevich. - M: Transport, 296.

4. Degtyarenko V.N. (1997). Organization of cargo transportation. V.N. Degtyarenko, V.V. Zimin, A.I. Kostenko. - M: Strix, 446.

5. Ilovaisky N.D. (2003). Service on transport (railway): Textbook for University Students Railway Transport. N.D. Ilovaisky, A.N. Kiselev. - M: Route, 583. 
6. Innovative processes of logistics management in intelligent transport systems / ed: B.A. Levin, L.B. Mirotin. - M: UMC on education on the railway transport Vol. 2: Formation of sectoral logistics intelligent transport systems. - 2015. 343.

7. Korovyakovskaya Yu. V., Malikov O.B. (2002). The role of warehouses in transport networks. Collection of scientific papers "Actual problems of management of the transportation process." - SPb: PGUPS, 1, $157-164$.

8. Korovyakovskaya Yu. R, Malikov O.B. (2003). Warehouse complexes as elements of the logistics chain. Bulletin of engineers of railway transport electromechanics. Samara: SamGAPS, 1, 222-224.

9. Korovyakovskaya Yu. V., Malikov O.B. (2004). Analysis of existing methods for calculating the capacity of warehouses. Collection of scientific papers "Actual problems of management of the transportation process."- SPb: PGUPS, 3, 162-168.

10. Kudryavtsev, V.A. (2003). Traffic control in railway transport. Tutorial - M: Route, 2003. 200.

11. Leontiev R.G. (2008). Transport and logistics of the Russian Far East: transport complex and land communications: monograph. R.G. Leontiev. - Khabarovsk: Publishing house of the Far Eastern State University of Railways, 259.

12. Logistics: Textbook. (2002). Ed. B.A. Anikina: 3rd ed., Revised and add. - M: INFRA-M, 368.

13. Malikov, O.B. (2003). Business logistics - SPb: Polytechnic, 223.

14. Manzhosov, G.P. (2002). Modern warehouse. Organization and technology - M: KIA center, 224.

15. Nerush, Yu. M. (2014). Logistics: a textbook for academic baccalaureate. Yu. M. Nerush, A. Yu. Nerush. - 5th ed., Rev. and add. - Moscow: Yurayt Publishing House, 559.

16. Organization of transportation and management of transport (railway transport). A.F. Borodin, A.P. Baturin, V. V. Panin. - M: MIIT, 2008. 192.

17. Osipov V.T., Povorozhenko V.V. Warehouses and transport and warehouse operations abroad. -M: Transport, 1983. 255.

18. Pashkov AK, Polyarin Yu. N. (2000). Packing and transportation of packaged goods - M: Transport, 254.

19. Pravdin N.V. (1987). Forecasting of cargo flows. N.V. Pravdin, M.L. Dykanyuk, V. Ya. Negrey. - M: Transport, 246.

20. Reser SM Logistics of freight forwarding, (2002). - Moscow: VINITI RAN, 472.

21. Ryzhikov Yu. I. (2001). Theory of queues and inventory management - SPb: Peter, 384.

22. Savin V.I. (2001). Warehouses: A Reference Guide - M: Publishing house "Business and Service", 2001. $-544$.

23. Semenenko A.I., Sergeev V.I. (2003). Logistics. Fundamentals of Theory: Textbook for Universities $\mathrm{SPb}$ : Publishing house "Soyuz", - 544.

24. Sergeev V.I. (2001). Logistics in business - M: Infra-M, 608.

25. Laughter A.A. (1995). Fundamentals of transport logistics: Textbook for universities railway transport M: Transport, 196.

26. Stoke, J.R., Lambert, D.M. (2005). Strategic logistics management. per. from English - M .: Infra-M, 797.

27. Economics of passenger transport: textbook. (2017). Ed. prof. V.A. Persianov. - 2nd ed., Erased. - M: KNORUS, 390.

28. Yaroshevich V.P., Shkurin M.I. (2001). Transport. General course: Textbook for students of transport specialties of universities. -Gomel: Belarusian State un-t transp., 389. 